\title{
ARTICLE \\ The COVID-19 multiplier effects of tourism on the German and Spanish economies
}

\author{
Nikolaos Rodousakis $^{1}$ (D) George Soklis $^{1}$
}

Received: 10 April 2021 / Accepted: 16 August 2021 / Published online: 29 August 2021

(c) Japan Association for Evolutionary Economics 2021

\begin{abstract}
Based on a multisectoral model of single production and using data from the inputoutput tables, this paper estimates the COVID-19 tourism multiplier effects on output, employment and trade balance of the German and Spanish economies. It is found that the decrease of international travel receipts recorded in the year 2020 correspond to a decrease in GDP of about $0.58 \%$ in the German economy and a decrease in GDP of about $4.54 \%$ in the Spanish economy. The evaluation of the results reveals that the higher observed recession in the Spanish economy than in the German economy can be attributed to the relatively stronger dependency of the former on the highly vulnerable in the pandemic tourism industry.
\end{abstract}

Keywords COVID-19 · German economy · Matrix demand multiplier · Spanish economy $\cdot$ Tourism

JEL Classification C67 · D57 · E11 · E61

\section{Introduction}

The coronavirus pandemic (COVID-19) has not only had a significant impact on public health, but it has also severely affected one of the linchpins of the European Union (EU) economy-the tourism sector. According to the latest data from Eurostat, $10 \%$ of the EU non-financial business economy belonged to the tourism

\footnotetext{
A first draft of this paper was presented at a Workshop of the Study Group on Sraffian Economics at the Panteion University, in January 2021. We are grateful to the participants for helpful remarks and discussions. We are also grateful to four anonymous reviewers for very helpful comments and suggestions. The usual disclaimer applies.

Nikolaos Rodousakis nrodousakis@kepe.gr

George Soklis gsoklis@kepe.gr

1 Centre of Planning and Economic Research (KEPE), Amerikis str. 11, 10672 Athens, Greece
} 
industries, employing 12.3 million people; $75 \%$ of those industries operated in accommodation (14\%) or food and beverage serving (61\%) activities, while 55\% of them were located in Italy, France, Spain and Germany. ${ }^{1}$ As many countries have introduced curfews and travel restrictions to contain the spread of the coronavirus, international travels have come to an almost complete standstill. Moreover, the longlasting lockdowns imposed in many countries also disturbed the supply chain of the tourism industry, since many tourism related activities were put on hold. The latest data from the World Tourism Organization (UNWTO) show that the international arrivals in Europe dropping by 70\%: in Western Europe by 65\%; in Southern Europe by $71 \%$; in Northern Europe by $75 \%$; and in Central Europe by $70 \%$. More than a half of the loss of worldwide international arrivals ( -1.07 billion persons) belongs to Europe $\left(-0.52\right.$ billion persons). ${ }^{2}$ Thus, while the countries were seeing a novice drop in tourist arrivals, all the sectors that depend on tourism activities are facing similar setbacks, ranging from closures in the food services to decreasing guest numbers in the accommodation (see e.g., Škare 2020). ${ }^{3}$

During the pandemic, a significant number of studies explore the decline of tourism activities and the corresponding impact on the economic system (see, e.g., Farzanegan et al. 2020; Lee and Chen 2020; Mariolis et al. 2020; Qiu et al. 2020; Tsionas 2020; Yang et al. 2020). The purpose of this paper is to provide estimations for the COVID-19 tourism multiplier effects on output, employment and trade balance of the German and Spanish economies. Since tourism has become an important part of economic activities during the last decades, it is reasonable to expect that the COVID-19 shock on the tourism sector will significantly affect the economic system due to (a) the loss of jobs in tourism, which will reduce incomes of the people involved in the tourism industry and, therefore, will diminish aggregate consumption; and (b) the fall in demand for intermediate inputs by the sectors that supply inputs to the tourism industry. Thus, it is important to study the intersectoral effects of the decline in tourism activities. For this purpose, we follow the approach of Mariolis et al. (2020), i.e., we use an analytic framework inspired by the concept of the Sraffian multiplier (Kurz 1985; Metcalfe and Steedman 1981; Mariolis 2008a) and data from the Symmetric Input Output Tables (SIOTs) for the year 2015 (latest data at the time of this research) provided via the Organisation for Economic Cooperation and Development (OECD) website, https://stats.oecd.org. As it has been demonstrated, the multiplier for real-world economies does not constitute a scalar, but a matrix quantity reflecting, in a complex way, the underlying inter-industry socio-technical linkages. It could, furthermore, be shown that the Sraffian multiplier

\footnotetext{
1 The data were retrieved from https://ec.europa.eu.

2 The data were retrieved from https://www.unwto.org.

${ }^{3}$ The COVID-19 crisis challenges the viability of old regime of European production system. European tourism struggles to recover, although there are some promising signs for a "tourism reset". According to European Travel Commission (2021) the pandemic created an opportunity for a more sustainable European tourism, focusing on responsible travel, on environmental, social and economic basis. After months of lockdowns there is of course a strong desire for travel and Europeans demonstrate their enthusiasm for hosting travelers, with $40 \%$ of respondents wanting to have more tourists visiting their community or country. There is of course the fear of overcrowding, as the pandemic is still with us, so $44 \%$ of respondents consider off season travel and $32 \%$ are willing to spend more to visit less crowded destinations.
} 
includes as special versions or limit cases the usual Keynesian multiplier, the multipliers of the traditional input-output analysis, and their Marxian versions. ${ }^{4}$ Since Germany (Spain) is characterized by a relatively low (high) dependency on the tourism sector, this empirical analysis will reveal whether the differences in the downturn within the EU economy can be attributed to the degree of the dependency of the economies on tourism activities. 5

The remainder of the article is structured as follows. The second section presents the method. The third section presents the empirical estimations. The fourth section concludes.

\section{The analytical framework}

We consider an open, linear economy involving only single products, "basic" commodities (in the sense of Sraffa 1960, pp. 7-8). In addition, we assume that (i) all capital is circulating; (ii) the input-output coefficients are fixed; (iii) there are noncompetitive imports; (iv) the net product is distributed to profits and wages that are paid at the end of the common production period; (v) the price of a commodity obtained as an output at the end of the production period is the same as the price of that commodity used as an input at the beginning of that period ("stationary prices"); and (vi) labour is homogeneous within each industry but heterogeneous across industries. ${ }^{6}$

On the basis of these assumptions, the price side of the system is described by ${ }^{7}$

$$
\mathbf{p}=\mathbf{p} \mathbf{A}[\mathbf{I}+\hat{\mathbf{r}}]+\mathbf{w} \hat{\mathbf{l}}
$$

where $\mathbf{p}(>\mathbf{0})$ the $1 \times n$ vector of commodity prices, $\mathbf{A}(\geq \mathbf{0})$ the $n \times n$ matrix of total input-output coefficients, I the $n \times n$ identity matrix, $\hat{\mathbf{r}}\left(r_{j}>-1\right.$ and $\left.\hat{\mathbf{r}} \neq \mathbf{0}\right)$ the $n \times n$ diagonal matrix of the sectoral profit rates, $\mathbf{w}\left(w_{j}>0\right)$ the $1 \times n$ vector of money wage rates, $\hat{\mathbf{l}}\left(l_{j}>0\right)$ the $n \times n$ diagonal matrix of direct labour coefficients.

The quantity side of the system is described by

$$
\mathbf{x}^{T}=\mathbf{A} \mathbf{x}^{T}+\mathbf{y}^{T}
$$

and

\footnotetext{
${ }^{4}$ For other empirical applications based on the concept of the Sraffian multiplier, see Mariolis (2008b), Mariolis and Soklis (2018), Mariolis et al. (2018a; b; 2021), and Ntemiroglou (2016).

${ }^{5}$ For instance, Germany's gross domestic product (GDP) decreased by $4.9 \%$ in the year 2020 , while Spain's GDP decreased by $11 \%$, while similar divergence is observed between almost all the Northern and Southern European economies.

${ }^{6}$ In particular, assumptions (i), (ii), (iii) and (vi) are imposed by the available input-output table data, which provide no data on the fixed capital stock matrices, non-competitive imports, pure joint products, natural resources (such as land of different qualities), different types of labour employed within each industry, and consumption patterns associated with wages and profit.

7 Matrices (and vectors) are delineated in boldface letters. The transpose of a $1 \times n$ vector $\mathbf{x} \equiv\left[x_{j}\right]$ is denoted by $\mathbf{x}^{T}$, and the diagonal matrix formed from the elements of $\mathbf{x}$ is denoted by $\hat{\mathbf{x}}$. Finally, e denotes the summation vector, i.e. $\mathbf{e} \equiv[1,1, \ldots, 1]$, and $\mathbf{e}_{j}$ the $j$ - th unit vector.
} 


$$
\mathbf{y}^{T}=\mathbf{c}_{w}^{T}+\mathbf{c}_{p}^{T}-\mathbf{I m}^{T}+\mathbf{d}^{T}
$$

where $\mathbf{x}^{T}$ denotes the gross output vector, $\mathbf{y}^{T}$ the vector of net output, $\mathbf{c}_{w}^{T}\left(\mathbf{c}_{p}^{T}\right)$ the vector of consumption demand out of wages (profits), $\mathbf{I m}^{T}$ the import demand vector, and $\mathbf{d}^{T}$ the autonomous demand vector (government expenditures, investments and exports).

By taking into account Eqs. (1) and (2), we derive the following equation ${ }^{8}$ :

$$
\mathbf{y}^{T}=\Pi \mathbf{d}^{T}
$$

where $\Pi \equiv[\mathbf{I}-\mathbf{C}+\mathbf{M}]^{-1}$ denotes the $n \times n$ matrix of multipliers linking autonomous demand to net output. Furthermore, $\mathbf{C} \equiv\left(\mathbf{p c}^{T}\right)^{-1} \mathbf{c}^{T}\left[\mathbf{p}-\left(s_{w} \mathbf{w} \Lambda+s_{p} \mathbf{p} \tilde{\mathbf{H}}\right)\right]$ denotes the $n \times n$ matrix of total consumption demand, $\mathbf{c}^{T}$ the uniform consumption pattern (associated with the two types of income), $s_{w}\left(s_{p}\right)$ the saving ratio out of wages (profits), $\Lambda \equiv \hat{\mathbf{I}}[\mathbf{I}-\mathbf{A}]^{-1}$ the $n \times n$ matrix of "vertically integrated labour coefficients", and $\tilde{\mathbf{H}} \equiv \mathbf{A} \hat{\mathbf{r}}[\mathbf{I}-\mathbf{A}]^{-1}$ the $n \times n$ " $\hat{\mathbf{r}}$ - vertically integrated technical coefficients matrix". Finally, $\mathbf{M} \equiv \hat{\mathbf{m}}[\mathbf{I}-\mathbf{A}]^{-1}$ denotes the $n \times n$ matrix of total import demand, and $\hat{\mathbf{m}}$ the $n \times n$ diagonal matrix of imports per unit of gross output of each commodity. Therefore, the multiplier effects depend, in a rather complicated way, on the: (i) technical conditions of production; (ii) imports per unit of gross output; (iii) income distribution; (iv) savings ratios out of wages and profits; (v) consumption pattern; and (vi) physical composition of autonomous demand.

From Eq. (3) and given that $\mathbf{L}^{T} \equiv \hat{\mathbf{l}} \mathbf{x}^{T}$ denotes the vector of sectoral employment, we derive the equation:

$$
\mathbf{L}^{T}=\Lambda \Pi \mathbf{d}^{T}
$$

where $\Lambda \Pi$ denotes the $n \times n$ matrix of employment multipliers linking autonomous demand to total employment.

Furthermore, we derive the matrix multiplier linking autonomous demand to imports as

$$
\mathbf{I m}^{T}=\hat{\mathbf{m}}[\mathbf{I}-\mathbf{A}]^{-1} \Pi \mathbf{d}^{T}
$$

where $\hat{\mathbf{m}}[\mathbf{I}-\mathbf{A}]^{-1} \Pi$ denotes the $n \times n$ matrix of import multipliers linking autonomous demand to imports.

Finally, in the closed economy case, i.e., for $\hat{\mathbf{m}}=\mathbf{0}$ matrix of multipliers reduces to $\Pi_{c} \equiv[\mathbf{I}-\mathbf{C}]^{-1}$ and thus Eqs. (3) and (4) become

$$
\begin{gathered}
\mathbf{y}^{T}=\Pi_{c} \mathbf{d}^{T} \\
\mathbf{L}^{T}=\Lambda \Pi_{c} \mathbf{d}^{T}
\end{gathered}
$$

Now, to estimate the multiplier effects of international travel receipts on output, total employment and imports, we set $\mathbf{d}^{T}$ equal to the vector that gives the distribution

\footnotetext{
${ }^{8}$ For a detailed exposition, see Mariolis and Soklis (2018).
} 


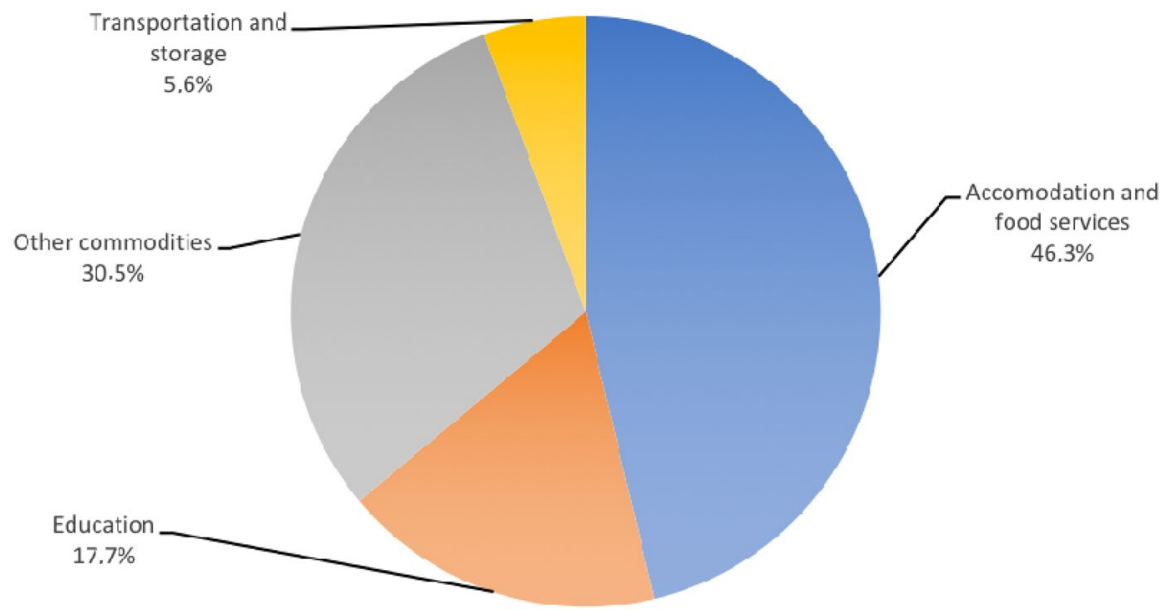

Fig. 1 Distribution (\%) of international travel receipts per commodity, Germany 2015

of international travel receipts to the 36 sectors that are described in the SIOTs of the economy of Germany and Spain. ${ }^{9}$ The elements of $\mathbf{d}^{T}$ are weighed by the total international travel receipts of the two economies and, therefore, the sum of the elements of $\mathbf{d}^{T}$ equal to 1 . The allocation of international travel receipts for the German economy to the commodities is depicted in Fig. 1: about $69.5 \%$ of the international travel receipts of the German economy corresponds to the commodities "Accommodation and food services" (46.3\%), "Education" (17.7\%), and "Transportation and storage" (5.6\%), while about $30.5 \%$ of the travel receipts is distributed to the rest of the 32 commodities. The allocation of international travel receipts for the Spanish economy to the commodities is depicted in Fig. 2: about $70.0 \%$ of the international travel receipts of the Spanish economy corresponds to the commodities "Accommodation and food services" (44.4\%), "Transportation and storage" (14.6\%), "Arts" (5.7\%), and "Real estate services" (5.3\%), while about $30.5 \%$ of the travel receipts is distributed to the rest of the 31 commodities.

\section{Empirical analysis}

We apply the previous analysis to the SIOT's of the German and Spanish economies for the case, where $s_{w}=0$ and $s_{p}=1{ }^{10}$ The empirical results indicate that a decrease in international travel receipts by 1 million euros would lead to a total (direct and indirect) $)^{11}$ :

\footnotetext{
${ }^{9}$ This information is derived from the column "Direct purchases by non-residents (exports)", which is part of the final demand in the input-output tables of OECD's database.

${ }^{10}$ Typical findings in many empirical studies suggest that $s_{w}<s_{p}$ and the difference between $s_{w}$ and $s_{p}$ is significant (say, in the range of 30\% to 50\%; see Onaran and Galanis 2012, and the references therein). Thus, we presume that the results for the (polar) case $s_{w}=0$ and $s_{p}=1$ are sufficiently representative.

11 The analytical results are available on request from the authors. For the construction of the relevant variables from the available input-output data we followed the usual procedure in the literature (see, e.g., Mariolis 2008b).
} 


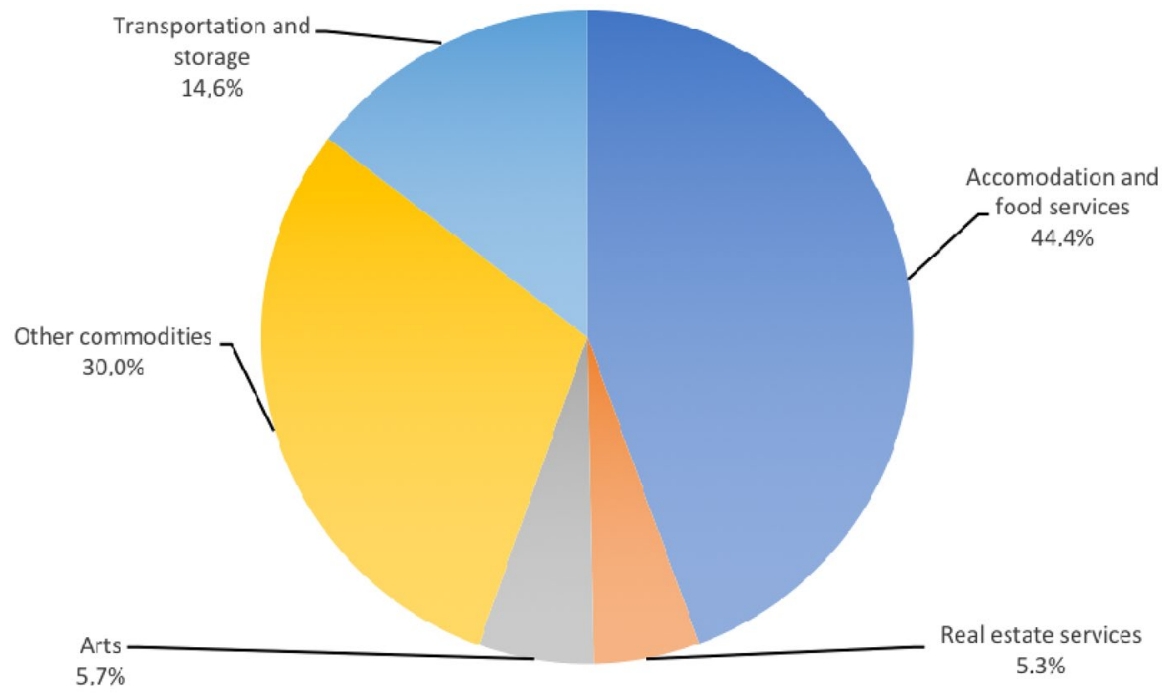

Fig. 2 Distribution (\%) of international travel receipts per commodity, Spain 2015

1. Decrease in net output of about 1.25 (1.33) million euros in the German (Spanish) economy

2. Decrease in employment of about 21.57 (21.93) people in the German (Spanish) economy.

3. Decrease in imports of about 0.42 (0.30) million euros in the German (Spanish) economy.

These findings indicate that the tourism multiplier effects are more significant in the Spanish than in the German economy, in the sense that Spain is characterized by a higher output and employment tourism multiplier and a lower import tourism multiplier. Nevertheless, in both economies, tourism can be characterized as a key-sector, in the sense that the output and employment tourism multipliers are above the economies' average multipliers and, at the same time, the import tourism multipliers are below the average import multipliers. Table 1 presents the average multipliers for the German and Spanish economies in comparison with the respective tourism multipliers.

Now, according to OECD, in the year 2019, Germany's GDP accounted for 4,153,928.4 million US dollars and total employment reached 42,400,100 persons. ${ }^{12}$ Moreover, according to World Tourism Organization (UNWTO), in the year 2019, Germany's international travel receipts reached 41.8 billion US dollars, while according to the latest available data travel receipts declined by $46 \%$ in the year 2020. ${ }^{13}$ From our analysis of the multiplier effects of international travel receipts on

\footnotetext{
12 The data were retrieved from https://stats.oecd.org.

13 See footnote4.
} 
Table 1 Average multipliers for the German and Spanish economies

\begin{tabular}{llll}
\hline & Output & Employment & Import \\
\hline Germany & $1.14[1.25]$ & $17.66[21.57]$ & $0.46[0.42]$ \\
Spain & $1.12[1.33]$ & $18.53[21.93]$ & $0.43[0.30]$ \\
\hline
\end{tabular}

Note: The values in square brackets indicate the respective tourism multipliers

the German economy, it then follows that this loss of travel receipts corresponds to a decrease in GDP of about $0.58 \%$, a decrease in the levels of employment of about $0.98 \%$, and a decrease in the surplus of the balance of goods and services of about 11.2 billion US dollars (19.228 billion US dollars decrease in exports minus 8.076 billion US dollars decrease in imports), respectively. In the polar (and hypothetical) case, where all the travel receipts (41.8 billion US dollars) are lost, our analysis indicates that GDP and employment in the German economy would decrease by $1.26 \%$ and $2.13 \%$, respectively, while the surplus of the balance of goods and services would decrease by 24.2 billion US dollars. According to same data sources, in the year 2019, Spain's GDP accounted for 1,796,023.9 million US dollars, total employment reached 19,779,300 persons, international travel receipts reached 79.7 billion US dollars, while according to the latest available data travel receipts declined by $77 \%$ in the year 2020. From our analysis of the multiplier effects of international travel receipts on the Spanish economy, it then follows that this loss of travel receipts corresponds to a decrease in GDP of about $4.54 \%$, a decrease in the levels of employment of about $6.80 \%$, and a decrease in the surplus of the balance of goods and services of about 43.0 billion US dollars (61.369 billion US dollars decrease in exports minus 18.411 billion US dollars decrease in imports), respectively. Finally, in the polar case, where all the travel receipts (79.7 billion US dollars) are lost, our analysis indicates that GDP and employment in the Spanish economy would decrease by $5.90 \%$ and $8.84 \%$, respectively, while the surplus of the balance of goods and services would decrease by 55.8 billion US dollars. Thus, given that Germany's (Spain's) GDP decreased by $4.9 \%$ (11\%) in the year 2020 , our estimations imply that the decline in inbound tourism accounts for about $11.8 \%$ (41.3\%) of the observed recession in the German (Spanish) economy.

To further delve into the differences between the tourism multiplier effects in Germany and Spain, we also estimate the economies' average and tourism multipliers for the closed economy case (Eqs. 6 and 7). Table 2 presents the closed-economy average multipliers for the German and Spanish economies in comparison with the respective tourism multipliers.

We observe that, in the closed-economy case, Germany is characterized by a higher output and employment multiplier of the tourism sector and by higher average output multiplier than Spain, while Spain is characterized by a higher average employment multiplier. Moreover, it is interesting to note that, in the closed-economy case, the tourism sector can be characterized as key-sector (anti-key-sector) for the German (Spanish) economy, since the output and employment multipliers of tourism are higher (lower) than the economy's average. 
Table 2 Closed-economy average multipliers for the German and Spanish economies

\begin{tabular}{lll}
\hline & Economy's Average & Tourism \\
\hline Germany & 0.577 & 0.578 \\
Spain & 0.489 & 0.521 \\
\hline
\end{tabular}

\begin{tabular}{lll}
\hline & Output & Employment \\
\hline Germany & $2.129[2.132]$ & $30.92[34.98]$ \\
Spain & $1.965[1.906]$ & $31.26[31.04]$ \\
\hline
\end{tabular}

Note: The values in square brackets indicate the respective tourism multipliers
Table 3 Wages per unit of output in the German and Spanish economies

Moreover, given that our estimates are based on the assumption that all wages are consumed and all profits are saved, it follows that the higher the wages paid per unit of output, $\mathbf{w} \Lambda$, the higher the multiplier effect. Table 3 reports the average wages paid per unit of output for each economy as well as the wages paid per unit of tourism output, i.e., $\mathbf{w} \Lambda \mathbf{d}^{T}\left(=1-\mathbf{p} \tilde{\mathbf{H}} d^{T}\right)$ for the case, where $\mathbf{d}^{T}$ is set equal to the vector that gives the distribution of international travel receipts.

We observe that Germany is characterized by relatively higher wages per unit of output, and that the tourism sector of both countries is characterized by higher wages per unit of output compared to the respective economy's average.

From the above, it follows that the relatively higher impact of the decline of international travel receipts in the Spanish economy than in the German economy can be attributed to (i) the relatively lower import multiplier of tourism in the Spanish economy, which leads to a higher open-economy output multiplier of tourism in the Spanish economy (Table 1); (ii) the relatively higher share of international travel receipts in total demand for the Spanish economy, which leads to higher total effects in the Spanish economy than in the German economy (1.26\% decline of GDP in the German economy in the polar scenario of a $100 \%$ loss in travel receipts, and $5.90 \%$ decline of GDP in the Spanish economy, respectively); and (iii) the relatively higher decline of international travel receipts in the Spanish economy than in the German economy in the year 2020 (77\% decline of international travel receipts in the Spanish economy, and $46 \%$ decline in the German economy).

Since it is not only important to focus on the aggregate effects of the decline in tourism activities but also on the intersectoral dimension of these effects, in Figs. 3 and 4, we present the distribution of the decrease in net output per commodity in the German (Spanish) economy; in Figs. 5 and 6, we present the distribution of the decrease in employment per sector in the German (Spanish) economy, and in Figs. 7 and 8, we present the distribution of the decrease in imports per commodity in the German (Spanish) economy.

From Figs. 3, 5, and 7, it is deduced that about 55.9\% of net output losses for the German economy correspond to "Accommodation and food services" (29.4\%), "Education" (14.2\%) and "Real estate services" (12.3\%), about 55.5\% of the 


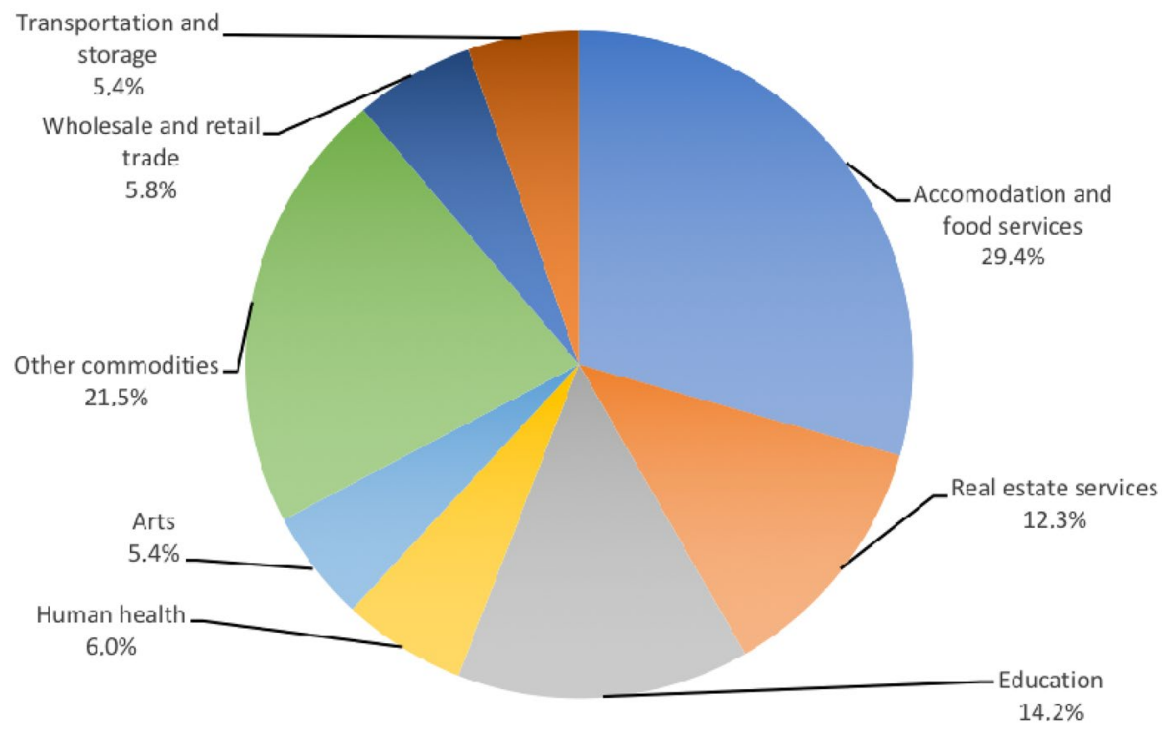

Fig. 3 Distribution (\%) of the output multiplier, Germany 2015

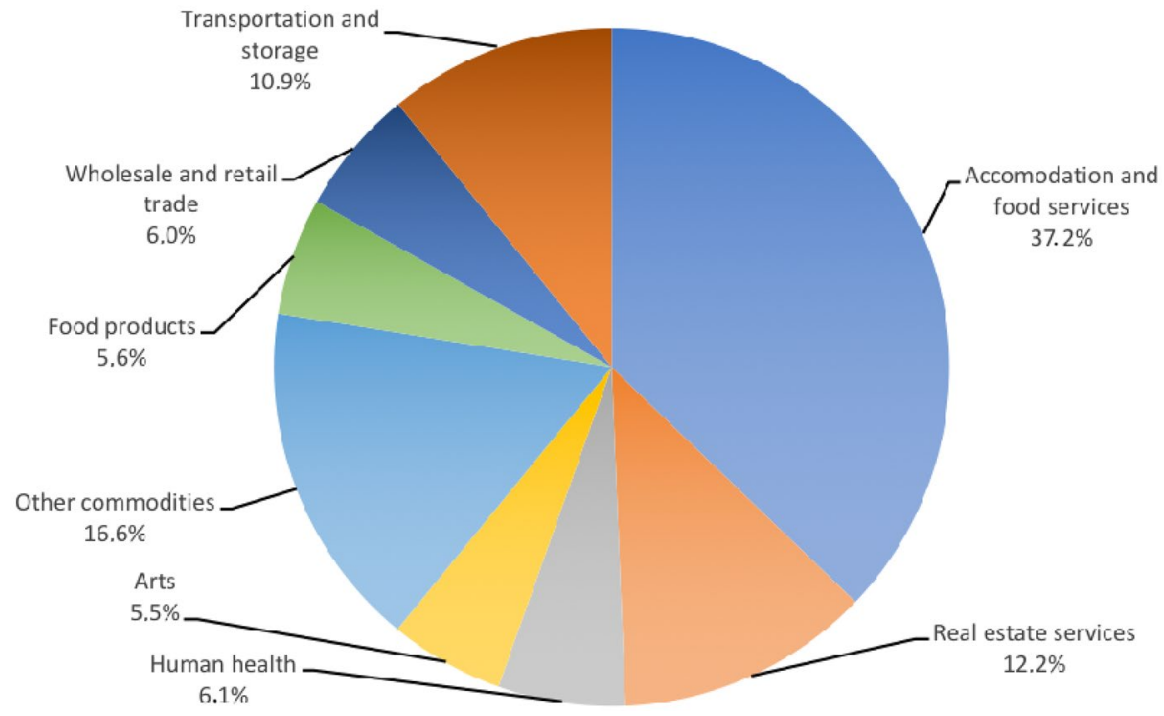

Fig. 4 Distribution (\%) of the output multiplier, Spain 2015

decreases in the levels of employment correspond to the sectors "Accommodation and food services" (33.4\%), "Education" (11.5\%) and "Wholesale and retail trade" (10.6\%), while the most significant decreases in imports correspond to "Accommodation and food services" (27.9\%), "Wholesale and retail trade" (9.7\%) and "Food products" (8.1\%). From Figs. 4, 6, and 8, it is deduced that about $60.3 \%$ of net output 


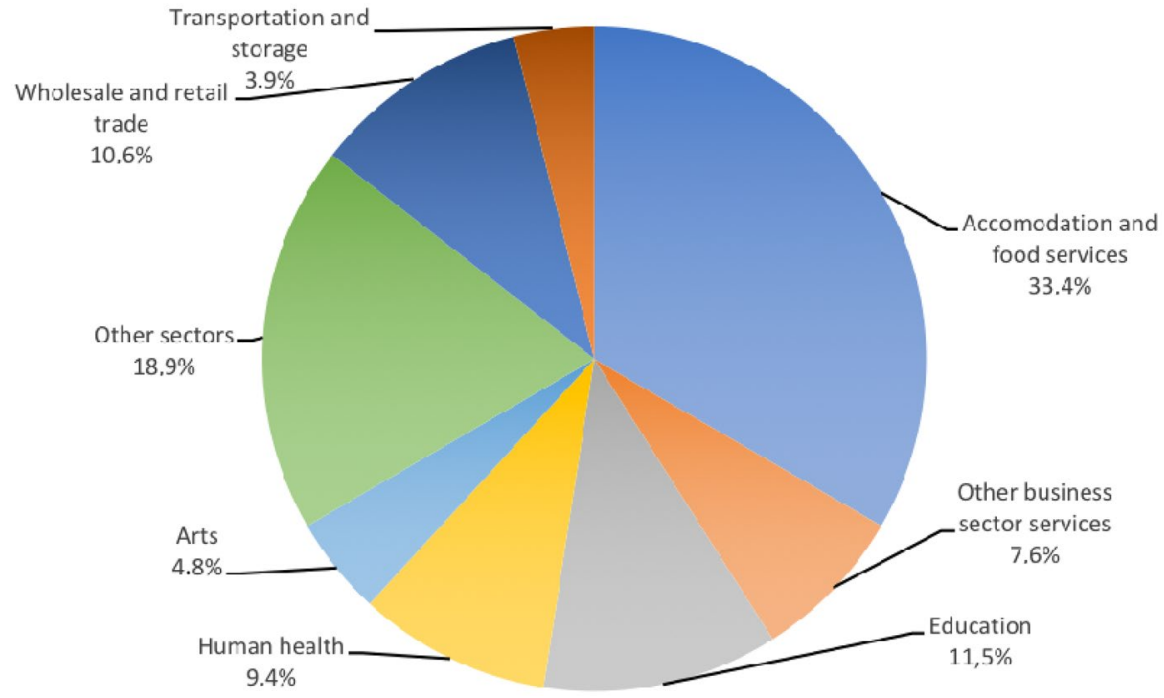

Fig. 5 Distribution (\%) of the employment multiplier, Germany 2015

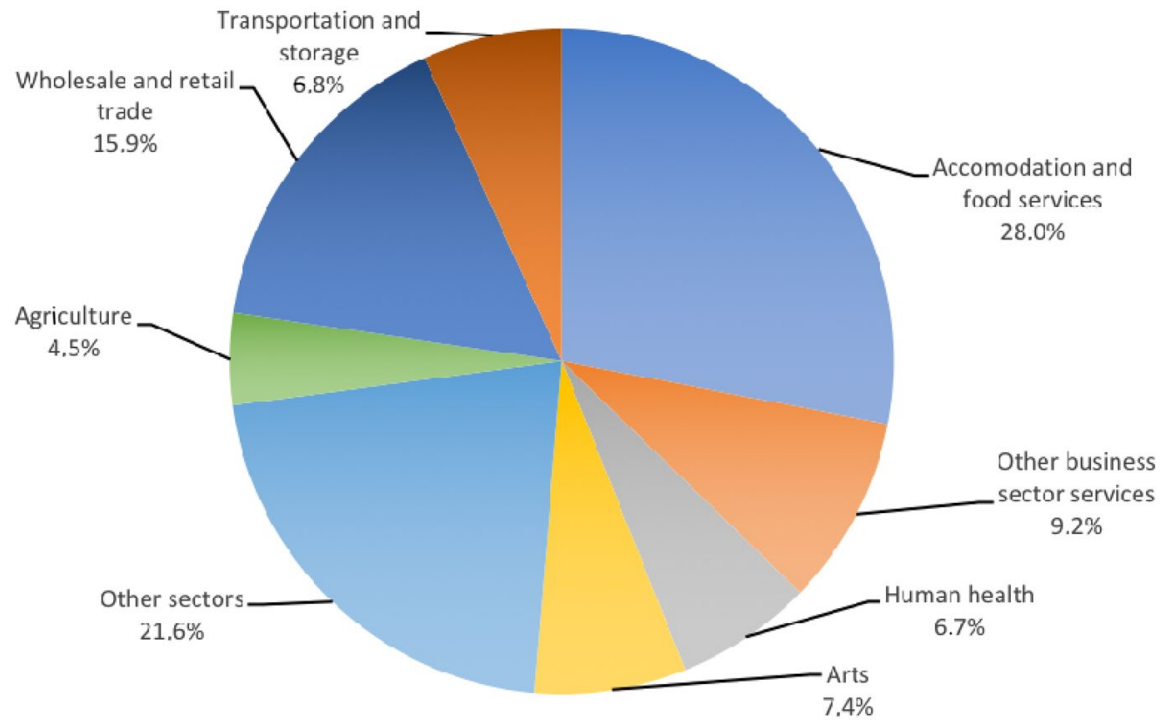

Fig. 6 Distribution (\%) of the employment multiplier, Spain 2015

losses for the Spanish economy correspond to "Accommodation and food services" (37.2\%), "Real estate services" (12.2\%) and "Transportation and storage" (10.9\%), about $52.5 \%$ of the decreases in the levels of employment correspond to the sectors "Accommodation and food services" (27.7\%), "Wholesale and retail trade" (15.7\%) 


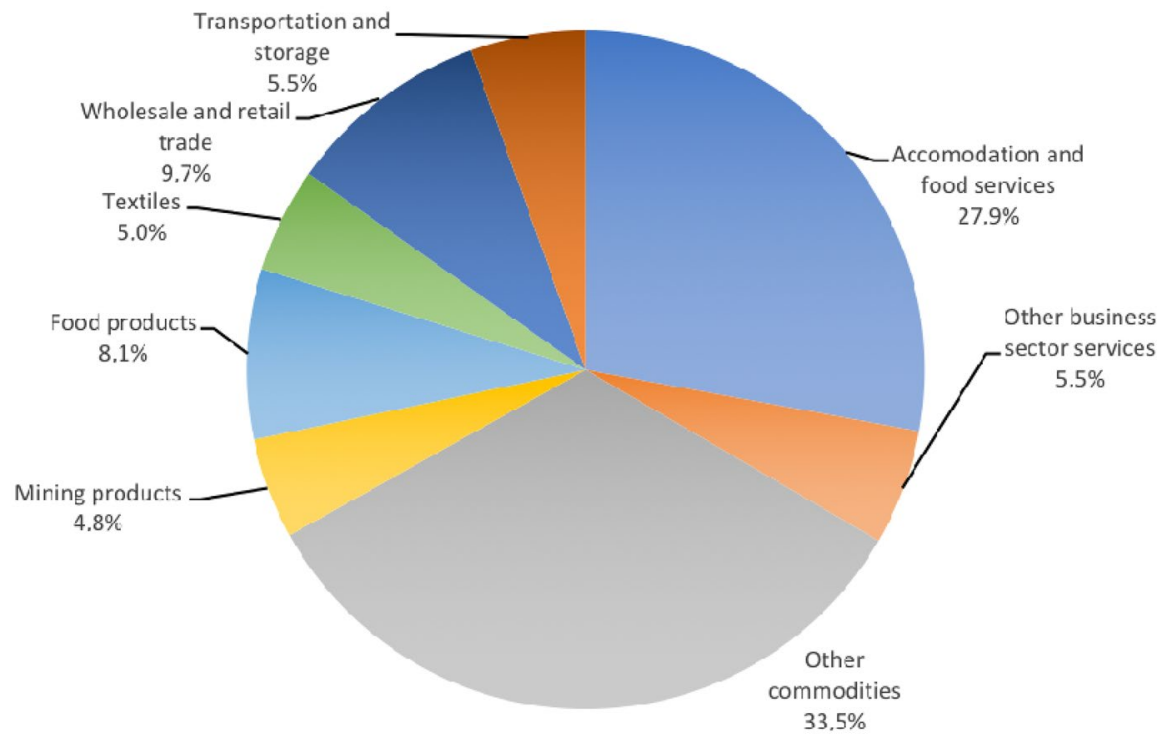

Fig. 7 Distribution (\%) of the import multiplier, Germany 2015

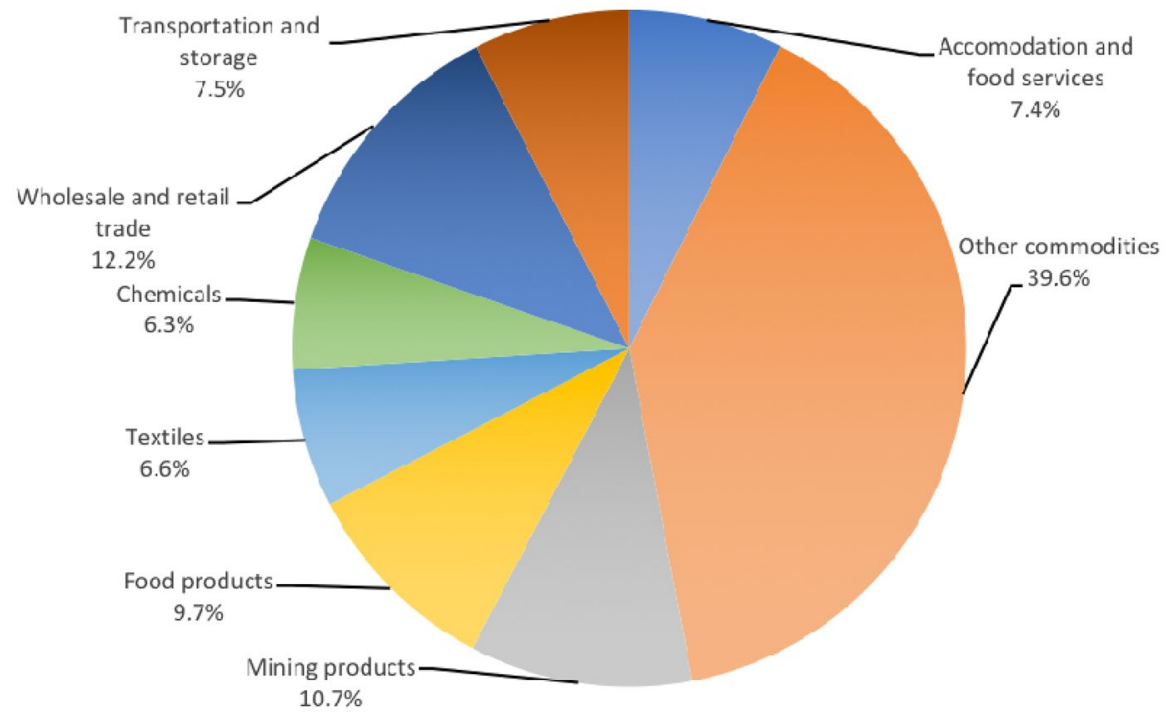

Fig. 8 Distribution (\%) of the import multiplier, Spain 2015

and "Other business sector services" (9.1\%), while the most significant decreases in imports correspond to "Wholesale and retail trade" (12.2\%), "Mining products" $(10.7 \%)$ and "Food products" $(9.7 \%)$. 
From the above, it follows that "Education" is a significant part of international travel receipts for Germany, both in terms of output and employment, while this is not true for the Spanish economy. This fact indicates that educational tourism is an important part of the German tourism industry. In addition, the relative importance of "Transportation and storage" is more significant, in terms of output and employment for the German than the Spanish economy. Finally, it is worth-mentioning that the "Accommodation and food services" is a significant part of the tourism import multiplier of the German economy but not for the Spanish economy.

It goes without saying that, although in this paper we focus on the ceteris paribus effects from a change in international travel receipts, this analytical framework can incorporate any shocks in the elements of autonomous demand and provide estimations for a vast range of alternative scenarios. For instance, the increase in government spending had a positive counter-impact on the economies (regarding both output and employment). In fact, our findings suggest that an increase in government spending by 1 million euros leads to a total (direct and indirect) increase in net output of about 1.53 (1.59) million euros in the German (Spanish) economy; an increase in employment of about 21.28 (27.47) persons in the German (Spanish) economy; and an increase in imports of about 21.28 (27.47) persons in the German (Spanish) economy. Thus, it follows that the multiplier effects of government spending on both economies are stronger than those of the tourism sector. ${ }^{14}$ Therefore, well-targeted fiscal policies and the implementation of appropriate sectoral redistributive policies could significantly offset some of the negative COVID-19 shocks.

\section{Concluding remarks}

This paper provided estimations of the effects of a decrease in international travel receipts on output, total employment and trade balance of the German and Spanish economies, using a multisectoral model of single production and data from the SIOT's for the year 2015. Based on the available facts and figures, it has been estimated that the decrease of international travel receipts recorded in the year 2020 in the German (Spanish) economy corresponds to a decrease in GDP of about $0.58 \%$ (4.54\%), a decrease in the levels of employment of about $0.98 \%(6.80 \%)$, and a decrease in the surplus of the balance of goods and services of about 11.2 (43.0) billion US dollars, respectively. These decreases mainly affect the sectors "Accommodation and food services", "Education", "Real estate services", and "Wholesale and retail trade" of the German economy, and the sectors "Accommodation and food services", "Real estate services", "Transportation and storage", and "Wholesale and retail trade" of the Spanish economy.

Although in both countries tourism can be characterized as a key-sector for effective demand management policy, the tourism multiplier effects are more significant in the Spanish than in the German economy, which is also reflected in our

\footnotetext{
14 The effects on employment of government spending on German economy are almost equal to those of the tourism sector.
} 
estimations for the contribution of the decline in international travel receipts to the observed recession in the two countries. Since Germany (Spain) can be considered as a sufficiently representative economy of a relatively low (high) dependency on the tourism sector, our results seem to be in accordance with the relative higher observed recession in the Southern European Economies, which are more dependent on the highly vulnerable in the pandemic tourism industry.

This modelling can easily incorporate a wide range of estimations for different countries, involving alternative scenarios for all the components of autonomous demand that hopefully will contribute to both the better understanding of the intersectoral dimensions of the decline in economic activities by the spread of COVID19 and the formulation of well-targeted recovery programs. Furthermore, future research efforts could extend the current framework to explore the COVID-19 international spillover effects by means of multi-country models and relevant inter-country input-output data.

Acknowledgements A first draft of this paper was presented at a Workshop of the Study Group on Sraffian Economics at the Panteion University, in January 2021. We are grateful to the participants for helpful remarks and discussions. We are also grateful to four anonymous reviewers for very helpful comments and suggestions. The usual disclaimer applies.

\section{References}

European Travel Commission (2021) European's attitudes towards responsible travel choices. https:// etc-corporate.org/reports/europeans-attitudes-towards-responsible-travel-choices/A. Accessed June 2021

Farzanegan MR, Gholipour HF, Feizi M, Nunkoo R, Andargoli AE (2020) International tourisn and outbreak of coronavirus (COVID-19): a cross-country analysis. J Travel Res. https://doi.org/10.1177/ 0047287520931593

Gil-Alana LA, Poza C (2020) The impact of COVID-19 on the Spanish tourism sector. Tour Econ. https://doi.org/10.1177/1354816620959914

Kurz HD (1985) Effective demand in a "classical" model of value and distribution: the multiplier in a Sraffian framework. Manch Sch 53(2):121-137. https://doi.org/10.1111/j.1467-9957.1985.tb01170

Lee CC, Chen MP (2020) The impact of COVID-19 on the travel and leisure industry returns: some international evidence. Tour Econ. https://doi.org/10.1177/1354816620971981

Mariolis T (2008a) Pure joint production, income distribution, employment and the exchange rate. Metroeconomica 59(4):656-665. https://doi.org/10.1111/j.1467-999X.2008.00320.x

Mariolis T (2008b) The Sraffian multiplier: Theory and application. Internal report of the study group on sraffian economics, 12 Nov 2008. Department of Public Administration Panteion University in Greek

Mariolis T, Soklis G (2018) The static Sraffian multiplier for the Greek economy: $\varepsilon v i d e n c e$ from the supply and use table for the year 2010. Rev Keynesian Econ 6(1):114-147. https://doi.org/10.4337/ roke.2018.01.07

Mariolis T, Ntemiroglou N, Soklis G (2018a) The static demand multipliers in a joint production framework: comparative findings for the Greek, Spanish and Eurozone Economies. J Econ Struc 7:18. https://doi.org/10.1186/s40008-018-0116-0

Mariolis T, Ntemiroglou N, Soklis G (2018b) The Sraffian autonomous demand-transfer payments curve for the Greek economy (in Greek). J Greek Stat Assoc 24-37:11-12

Mariolis T, Rodousakis N, Soklis G (2020) The COVID-19 multiplier effects of tourism on the Greek economy. Tour Econ. https://doi.org/10.1177/1354816620946547 
Mariolis T, Rodousakis N, Soklis G (2021) Inter-sectoral analysis of the Greek economy and the COVID19 multiplier effects. Euro Pol Soc. https://doi.org/10.1080/23745118.2021.1895555

Metcalfe JS, Steedman I (1981) Some long-run theory of employment, income distribution and the exchange rate. Manch Sch 49(1):1-20. https://doi.org/10.1111/j.1467-9957.1981.tb00169.x

Ntemiroglou N (2016) The Sraffian multiplier and the key-commodities for the Greek economy: evidence from the input-output tables for the period 2000-2010. Bullet Pol Econ 10:1-24

Onaran Ö, G Galanis (2012) Is aggregate demand wage-led or profit-led? National and global effects. Conditions of work and employment series No. 40, Geneva, International Labour Office

Qiu RTR, Park J, Li SN, Song H (2020) Social costs of tourism amid COVID-19 pandemic. Ann Tour Res 84:102994. https://doi.org/10.1016/j.annals.2020.102994

Škare M, Soriano DR, Porada-Rochoń M (2021) Impact of COVID-19 on the travel and tourism industry. Technol Forecast Soc Change. https://doi.org/10.1016/j.techfore.2020.120469

Tsionas M (2020) COVID-19 and gradual adjustment in the tourism, hospitality, and related industries. Tour Econ. https://doi.org/10.1177/1354816620933039

Williams CC (2021) Impacts of the coronavirus pandemic on Europe's tourism industry: addressing tourism enterprises and workers in the undeclared economy. Int J Tourism Res 23:79-88. https://doi.org/ 10.1002/jtr.2395

Yang Y, Zhang H, Chen X (2020) Coronovirus pandemic and tourism: dynamic stochastic general equilibrium modeling of infectious disease outbreak. Ann Tour Res 83:102913. https://doi.org/10. 1016/j.annals.2020.102913

Publisher's Note Springer Nature remains neutral with regard to jurisdictional claims in published maps and institutional affiliations. 